\title{
Modeling the Exchanges of Energy, Water, and Carbon Between Continents and the Atmosphere
}

\author{
P. J. Sellers, ${ }^{*}$ R. E. Dickinson, D. A. Randall, A. K. Betts, F. G. Hall, J. A. Berry, G. J. Collatz, \\ A. S. Denning, H. A. Mooney, C. A. Nobre, N. Sato, C. B. Field, A. Henderson-Sellers
}

\begin{abstract}
Atmospheric general circulation models used for climate simulation and weather forecasting require the fluxes of radiation, heat, water vapor, and momentum across the land-atmosphere interface to be specified. These fluxes are calculated by submodels called land surface parameterizations. Over the last 20 years, these parameterizations have evolved from simple, unrealistic schemes into credible representations of the global soil-vegetation-atmosphere transfer system as advances in plant physiological and hydrological research, advances in satellite data interpretation, and the results of largescale field experiments have been exploited. Some modern schemes incorporate biogeochemical and ecological knowledge and, when coupled with advanced climate and ocean models, will be capable of modeling the biological and physical responses of the Earth system to global change, for example, increasing atmospheric carbon dioxide.
\end{abstract}

Until the early 1980s, global atmospheric general circulation models (AGCMs) incorporated very simple land surface parameterizations (LSPs) to estimate the exchanges of energy, heat, and momentum between the land surface and the atmosphere. These have since evolved into a family of schemes that can realistically describe a comprehensive range of land-atmosphere interactions. These advanced schemes will be needed to understand the response of the biosphere and the climate system to global change, for example, increasing atmospheric $\mathrm{CO}_{2}(1-3)$.

Three generations of models have taken us from the early LSPs to where we stand now. The first, developed in the late 1960s and 1970s, was based on simple aerodynamic bulk transfer formulas and often uniform prescriptions of surface parameters (albedo, aerodynamic roughness, and soil moisture availability) over the

P. J. Sellers is at the NASA Johnson Space Center, Mail Code CB, Houston, TX 77058, USA. R. E. Dickinson is in the Department of Atmospheric Sciences, University of Arizona, Tucson, AZ 85721, USA. D. A. Randall is in the Atmospheric Sciences Department, Colorado State University, Fort Collins, CO 80523, USA. A. K. Betts is at Atmospheric Research, Rural Route 3, Box 3125, Pittsford, VT 05763, USA. F. G. Hall and G. J. Collatz are at NASA Goddard Space Flight Center, Code 923, Greenbelt, MD 20771, USA. J. A. Berry and C. B. Field are in the Department of Plant Biology, Carnegie Institution, Stanford, CA 94305, USA. A. S. Denning is in the School of Environmental Science and Management, University of California, Santa Barbara, CA 93106-5131, USA. H. A. Mooney is in the Department of Biological Sciences, Stanford University, Stanford, CA 94305, USA. C. A. Nobre is at INPE/CPTEC, Caixa Postal 01, cep 12630-000, Cachoeira Paulista, SP, Brazil. N. Sato is in the Numerical Prediction Division, Japan Meteorology Agency, 1-3-4, Ootemachi, Chiyoda-ku, Tokyo, Japan 100. A. Henderson-Sellers is at the Royal Melbourne Institute of Technology, Plenty Road, Post Office Box 71, Bundoora, VIC 3083, Australia.

*To whom correspondence should be addressed. continents (4). In the early 1980 s, a second generation of models explicitly recognized the effects of vegetation in the calculation of the surface energy balance (5, 6). At the same time, global, spatially varying data of land surface properties were assembled from ecological and geographical surveys published in the scientific literature (7). The latest (third generation) models use modern theories relating photosynthesis and plant water relations to provide a consistent description of energy exchange, evapotranspiration, and carbon exchange by plants $(8-10)$. Some are beginning to incorporate treatments of nutrient dynamics and biogeography, so that vegetation systems can move in response to climate shifts. A series of largescale field experiments have been executed to validate the process models and scaling assumptions involved in land-atmosphere schemes (3). These experiments have also accelerated the development of methods for translating satellite data into global surface parameter sets for the models.

\section{Theoretical Background and the First-Generation Models}

It has been understood for nearly 200 years that the continents and the atmosphere exchange energy, water, and carbon with each other. However, it was not until the late 1960s with the construction of the first AGCMs, in the guise of numerical weather prediction (NWP) models, that scientific interest became focused on how to describe these exchanges with useful accuracy.

In AGCMs, the motion of the atmosphere is defined by fluid dynamics equations that incorporate the mechanical forces of gravity, the Earth's rotation, pres- sure and temperature gradients, and friction $(2,11)$. Energy transfer processes include radiative heating and cooling; heat transport by means of convection, condensation, and evaporation; and the transfer of energy, water, and momentum across the lower boundary of the atmosphere, that is, between the land or ocean surfaces and the atmosphere. The AGCMs use three-dimensional grid systems to represent the vertical and horizontal structure and state of the atmosphere and integrate finite difference versions of the governing equations to predict successive states of the atmosphere. The early models typically used horizontal resolutions of around $10^{\circ}$ to $20^{\circ}$ in longitude and latitude, two to seven layers in the vertical, and time steps of about $30 \mathrm{~min}$. As computer performance improved, spatial resolutions for global NWP models were refined to around $1^{\circ}$ of horizontal resolution and 20 or more layers in the vertical. Time steps still range from a few minutes to a halfhour or so.

The coarse grids did not lend themselves to exacting validation. However, as the models improved along with their spatial resolutions, it became obvious that shortcomings in the description of many physical processes-such as radiative exchange, convection, and condensationwere at least as important as the fluid dynamics problems that had absorbed most of the early scientific effort (2). With regard to land-atmosphere interactions, the important processes from the AGCM point of view were (i) the exchanges of radiation, (ii) the fluxes of sensible and latent heat (evapotranspiration) between the surface and atmosphere, and (iii) the frictional deceleration of the lower atmosphere resulting from drag forces as the wind passes over the land. All three of these processes are closely related through a simple set of equations.

The net amount of radiant energy absorbed by the land surface and available for transfer into other energy forms is defined as the sum of the absorbed solar energy and the absorbed downwelling long-wave radiation emitted by the overlying atmosphere minus the long-wave radiation emitted by the surface (Fig. 1A)

$$
R_{\mathrm{n}}=S(1-\alpha)+L_{\mathrm{w}}-\varepsilon \sigma T_{\mathrm{s}}^{4}
$$


where $R_{\mathrm{n}}$ is the net radiation, $S$ is the insolation, $\alpha$ is the surface albedo, $L_{\mathrm{w}}$ is the downward long-wave flux, $\varepsilon$ is the surface emissivity $(\cong 1.0), \sigma$ is the Stefan-Boltzmann constant, and $T_{\mathrm{s}}$ is the land surface temperature. Insolation $S$ is calculated as a function of latitude, longitude, time of day, and the cloudiness simulated or prescribed within the AGCM; $L_{w}$ is a function of the temperature, humidity profile, and cloudiness of the atmosphere; and $T_{\mathrm{s}}$ is usually predicted (time stepped) within the model. From Eq. 1 we see that the land surface parameter that has the most influence on the surface radiation budget is the albedo $\alpha$, which is defined as the integrated reflectance of the surface over the solar spectrum (0.0 to $4.0 \mu \mathrm{m})$.

Radiation $R_{n}$ is partitioned into three (nonradiation) heat flux terms

$$
R_{\mathrm{n}}=\mathrm{G}+\mathrm{H}+\lambda E
$$

where $G$ is the ground heat flux, $H$ is the sensible heat flux, $E$ is the evapotranspiration rate, and $\lambda$ is the latent heat of vaporization. The calculation of $G$ has generally been approached as a simple heat diffusion problem. The early models used two-layer force-restore schemes (12), which crudely simulated the diurnal and seasonal components of the ground heat flux. Many LSPs
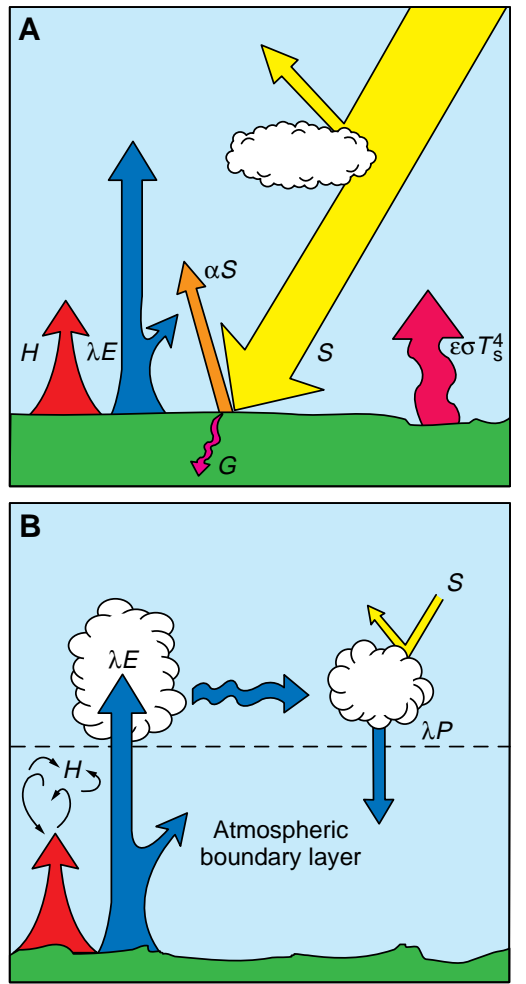

Fig. 1. Interactions between the land surface and the atmosphere that have direct impacts on the physical climate system. (A) Surface radiation budget. (B) Effect of heat fluxes on the atmosphere. have moved on to incorporate multilayer descriptions of coupled heat and moisture flow, together with descriptions of the effects of snowmelt and water phase changes within the soil profile (13). Generally, $\mathrm{G}$ is a small proportion, $10 \%$ or less, of $R_{n}$ when averaged over a diurnal cycle but can be an important term in the seasonal energy budget.

The fluxes of $H$ and $\lambda E$ have profound effects on weather and climate (Fig. 1B). The sensible heat released from the land surface raises the temperature of the overlying air column and warms the planetary boundary layer. The latent heat flux $\lambda E$ is the energy equivalent of the water evaporated from the surface or transpired through vegetation (the term evapotranspiration covers both sources of moisture). The evaporated water vapor is often transported to great heights through convection, releases heat to the atmosphere during condensation, forms clouds (which have strong effects on the atmospheric radiation budget), and produces precipitation $P$. Thus, unlike sensible heat, the release of latent heat from the surface usually has a nonlocal impact on the atmosphere.

Given the different and important roles of sensible and latent heat within the climate system, Eq. 2 should be solved as accurately as possible over all surface gridpoints within an AGCM. In the first models, transports of $H$ and $\lambda E$ were commonly treated as quasi-diffusive processes, which can be written in the potential difference resistance form (Fig. 2A)

$$
\begin{gathered}
H=\frac{T_{\mathrm{s}}-T_{\mathrm{r}}}{r_{\mathrm{a}}} \rho c_{\mathrm{p}} \\
\lambda E=\beta\left[\frac{e^{*}\left(T_{\mathrm{s}}\right)-e_{\mathrm{r}}}{r_{\mathrm{s}}}\right] \frac{\rho c_{\mathrm{p}}}{\gamma}
\end{gathered}
$$

where $T_{r}$ is the air temperature within the lowest layer of the atmospheric model, $r_{\mathrm{a}}$ is the aerodynamic resistance between the surface and the lowest layer of the atmosphere, $\rho$ and $c_{\mathrm{p}}$ are the density and specific heat of air, $\beta$ is the moisture availability function $(0 \leq \beta \leq 1), e^{*}\left(T_{\mathrm{s}}\right)$ is the saturated vapor pressure at temperature $T_{s}, e_{r}$ is the vapor pressure within the lowest layer of the atmospheric model, and $\gamma$ is the psychrometric constant.

Thus, $H$ is proportional to the difference between surface and atmospheric temperatures and inversely proportional to an aerodynamic resistance $r_{\mathrm{a}}$, which can be thought of as a turbulent diffusionrelated term impeding the transfer of heat or mass from the surface to the air. Almost all of the first AGCMs made use of Eq. 4 to describe evapotranspiration; it is a direct analog of Eq. 3 except that water vapor pressure replaces temperature and the land surface is assumed to be a saturated source of water $\left[e^{*}\left(T_{s}\right)\right]$. A moisture availability term, $\beta$, was included to reduce evaporation rates in dry areas $(4,14)$, and an accounting procedure for soil moisture, $W$, was applied to each grid square, whereby the soil column was depleted by evapotranspiration and replenished by precipitation up to a maximum capacity $W_{\text {max }}$, after which excess precipitation was assumed to run off as streamflow. The value of $\beta$ was usually set to unity when the so-called "bucket" model was "full" $\left(W=W_{\max }\right)$ and to zero when empty. A variety of functions was proposed to describe $\beta$ for intermediate cases (Fig. 2A).

The aerodynamic resistance $r_{\mathrm{a}}$ is commonly derived from simple turbulence models. It is inversely dependent on wind speed $u_{\mathrm{r}}$ and the logarithm of the surface roughness length $z_{0} ; z_{0}$ is a function of the drag properties of the land surface and is about $10 \%$ of the vegetation height. Stability corrections are applied to account for the effects of convection on $r_{\mathrm{a}}$ because large fluxes of $H$ can significantly augment turbulent transfer and reduce $r_{\mathrm{a}}(15)$. The frictional stress $\tau$ exerted by the land surface on the atmosphere is proportional to $u_{\mathrm{r}} / r_{\mathrm{a}}$; many formulations also account for differences between the transports of heat, water vapor, and momentum in $r_{\mathrm{a}}$

Inspection of Eqs. 1 through 4 shows how the atmospheric forcing variables $(S$, $L_{\mathrm{w}}, T_{\mathrm{r}}, e_{\mathrm{r}}, u_{\mathrm{r}}$, and $P$ ) are used to calculate the energy available to the surface $\left(R_{n}\right)$ and the fluxes $(H, \lambda E, G$, and $\tau$ ) given the surface parameters $\left(\alpha, z_{0}\right.$, and $\left.W_{\max }\right)$ : To begin with, $\alpha$ and $z_{0}$ were simply prescribed as global, often uniform, fields, and $W_{\max }$ was set to a single value, typically $150 \mathrm{~mm}$, everywhere.

A computer code incorporating these equations or their analogs is referred to as an LSP. The first-generation LSPs were used to explore the roles of albedo, surface roughness, and moisture availability in AGCM climatologies (16).

The land surface albedo varies from about 9 to $12 \%$ (boreal and tropical forests) to around 35\% (Sahara desert) over the snow-free land $(7,17,18)$. Some AGCM sensitivity experiments that focused on albedo changes in the SahelSahara region indicated that an increase in the regional albedo would lead to decreases in the surface evaporation and precipitation rates in the same area $(19,20)$. In another study, the roughness length $z_{0}$ of the world's deserts was reduced from 45 $\mathrm{cm}$ to $0.2 \mathrm{~mm}$, which improved the simulated fields of horizontal water vapor convergence and convective precipitation (21). Many sensitivity studies have fo- 
cused on the role of soil moisture in controlling sensible and latent heat fluxes between the surface and atmosphere (20, 22). Experiments ranged from global prescriptions of totally wet versus totally dry land surfaces to alterations in regional soil moisture capacities. In almost all of the simulations, reduced land surface evaporation rates led to reduced precipitation rates in the continental interiors.

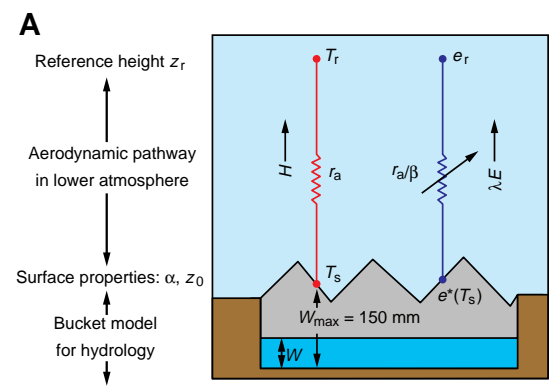

B
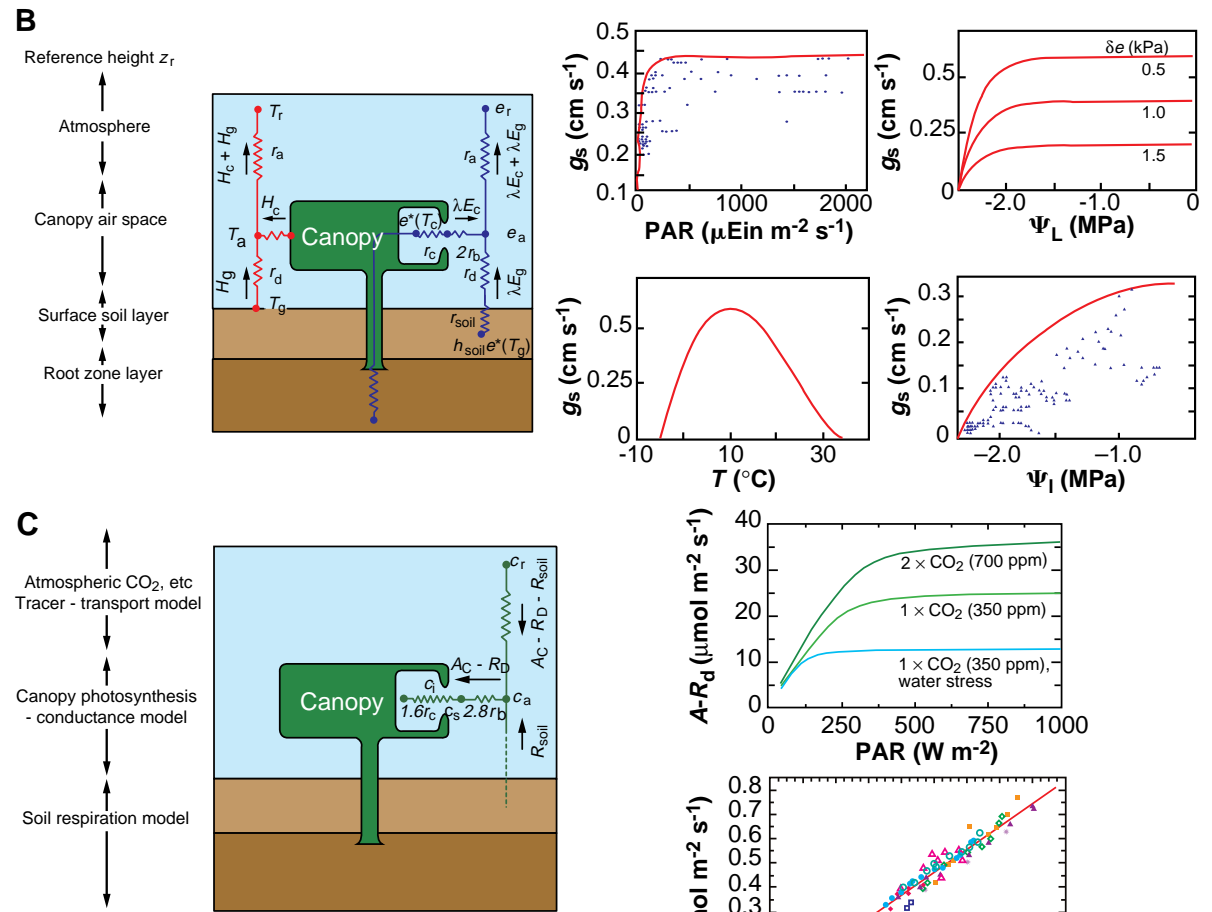

Fig. 2. Development of LSPs in AGCMs. (A) First-generation "bucket" model (4). (Left) The sensible and latent fluxes flow from the surface to the atmosphere through an aerodynamic resistance $r_{\mathrm{a}}$. (Right) The latent heat
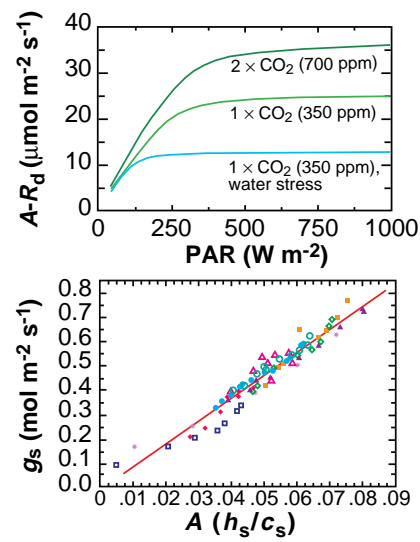

flux is regulated by the level of moisture $W$ in the bucket through the moisture availability function $\beta$. (B) Second-generation model $(5,6)$ with separated vegetation canopy and soil. Moisture fluxes from the (dry) vegetation canopy escape to the canopy air space and free atmosphere through a bulk canopy surface resistance $\left[r_{c}=1 / g_{c}(29)\right]$. Sensible and latent heat fluxes from the ground (subscript " $g$ ") and canopy (subscript "c") combine in the canopy air space to give the total fluxes passed to the atmosphere. (Right) Terms in Eq. 6 that relate leaf conductance $\left(g_{s}\right)$ to light intensity (PAR), vapor pressure deficit ( $\delta e)$, temperature $(T)$, and leaf water potential $\left(\Psi_{)}\right)$. [Redrawn with permission from (25)] The points denote observations; the lines denote a hypothetical limit to the $f\left(\Psi_{1}\right)$ relation. The canopy resistance $r_{c}$ can be calculated by integrating $g_{s}$ over the depth of the canopy and inverting it $(27,28)$. (C) Thirdgeneration model $(8,10)$. A carbon flux pathway is added to the moisture and heat flux pathways shown in (B). (Left) The canopy $A-g_{s}$ model controls canopy carbon and water fluxes simultaneously and consistently. (Upper right) Dependence of leaf assimilation $A$ on light (PAR) intensity, $\mathrm{CO}_{2}$ concentration, and water stress. (Lower right) Relation between $g_{s}$ and $A$ for a number of species, with a line of best fit (see also Eq. 7). sensible and latent heat, and momentum across the lower boundary of the atmosphere were treated as independent processes $(5,23)$.

In nature, plants are not the passive, spongelike structures implied by the firstgeneration bucket models, in which the vegetation was viewed as a pervious sheet separating the soil from the atmosphere (Fig. 2A). Consequently, the strategy adopted in formulating the second-generation biophysical LSPs $(5,6)$ was to model the vegetation-soil system itself and let this determine the ways in which the land surface interacts with the atmosphere (Fig. 2B). These interactions can be summarized as follows.

1) Radiation absorption. The spectral properties of leaves and multiple reflections between them make vegetative canopies highly absorbent in the visible [photosynthetically active radiation (PAR)] wavelength interval $(0.4$ to $0.72 \mu \mathrm{m})$ and moderately reflective in the near-infrared region $(0.72$ to $4.0 \mu \mathrm{m})$. In contrast, bare ground generally exhibits a gradual increase in reflectivity with wavelength between 0.4 and $4.0 \mu \mathrm{m}$.

2) Momentum transfer. Vegetative canopies usually present a rough, porous surface to the planetary boundary layer airflow. The resultant turbulence enhances the transport of sensible and latent heat away from the surface while exerting a drag force that may be significantly larger than that produced by bare ground.

3) Biophysical control of evapotranspiration. Plant metabolism is based on the photosynthetic reaction, in which shortwave radiation energy is used to combine water and atmospheric $\mathrm{CO}_{2}$ into sugars and other organic compounds. To do this, plants must allow for the transfer of $\mathrm{CO}_{2}$ from the atmosphere to the cellular sites of photosynthesis located inside the leaves. This flow requires an open pathway between the atmosphere and the water-saturated tissues inside the leaf, which leads to an inevitable loss of water vapor over the same route (Figs. 2B and 3). Higher plants regulate the amount of gas exchange (and hence water loss) by means of adjustable valvelike structures on the leaf surface called stomates. When the first biophysical LSPs were being formulated in the 1980s, working hypotheses for quantitatively describing the linked photosynthesis-stomatal conductance system were in the early stages of development (24) and were not yet recognized by the climate community. However, empirical work (25) had correlated stomatal conductance $g_{s}$ (the conductance of the leaf stomates to the passage of water vapor from the saturated leaf interior to the free air just outside the leaf) to the environmental con- 
ditions that control photosynthesis (Fig. 2B).

$$
g_{\mathrm{s}}=g_{\mathrm{s}}(\mathrm{PAR})\left[f(\delta e) f(T) f\left(\Psi_{1}\right)\right]
$$

where $g_{\mathrm{s}}(\mathrm{PAR})$ is the PAR-regulated (unstressed) value of leaf conductance and $f(\delta e), f(T)$, and $f\left(\Psi_{1}\right)$ are the environmental stress factors that account for the effects of vapor pressure deficit $\delta e$, temperature $T$, and leaf water potential $\Psi_{1}$, respectively.

Equation 5 captures the important responses of leaf stomates to the environment. As PAR (sunlight) increases, the unstressed leaf prepares for photosynthesis by opening its stomates, and so $g_{s}(P A R)$ monotonically increases from near zero at zero PAR to an asymptote at high light levels. The stress factors are all scaled between 1 , for optimal conditions, to 0 , when environmental conditions are severe enough to shut down photosynthesis and close the stomates (Fig. 2B, right). The $f(\delta e)$ term is particularly interesting: almost all plants maintain open stomates in humid air, when $\mathrm{CO}_{2}$ can be taken up freely with a relatively small loss of leaf water vapor. As the external air dries, the stomates progressively close, and $f(\delta e)$ decreases, presumably to protect the leaf from desiccation and to conserve water. The $f(T)$ function reaches a maximum around the mean environmental growing season temperature and tapers off to zero for warmer or cooler temperatures; this action is related to the enzyme kinetics of photosynthesis and conductance, which have been "tuned" through evolution to work efficiently at particular temperatures (in fact, this optimal temperature for a plant's enzymatic function can vary to accommodate seasonal and interannual temperature variations). The leaf water potential $\Psi_{1}$ represents the chemical energy of the liquid water in the leaf cells; its value has to be negative to ensure a continuous suction pathway of moisture from the root zone to the leaves (26). The stomates close when the soil moisture is limiting or when the transpiration rate is excessive, causing $\Psi_{1}$ to drop. The leaf-scale model of Eq. 5 has been modified by a number of techniques to provide a canopy-scale estimate of conductance $g_{c}$ (27). One scheme (28) assumes that the stress factors are near uniform and that PAR is attenuated exponentially down through the vegetation canopy, which permits analytical integration of Eq. 5 to yield an estimate of $g_{c}$ for a canopy of known leaf area index (LAI, the one-sided area of leaves per unit of ground area; dense vegetation has an LAI of around 5). The inverse of $g_{c}$ gives canopy resistance $r_{\mathrm{c}}=1 / g_{\mathrm{c}}$, which can be used to calculate evapotranspiration (29) (Fig. 2B). In the absence of significant soil evaporation, this takes the form

$$
\lambda E=\beta\left[\frac{e^{*}\left(T_{\mathrm{s}}\right)-e_{\mathrm{r}}}{r_{\mathrm{a}}+r_{\mathrm{c}}}\right] \frac{\rho c_{\mathrm{p}}}{\gamma}
$$

Equations 6 and 4 should be compared. Equation 4 has a moisture limitation term $\beta$, which is applied externally to an estimate of the maximum evaporation rate; by contrast, the use of $r_{\mathrm{c}}$ in series with $r_{\mathrm{a}}$ in Eq. 6 realistically separates aerodynamic and surface resistance terms (Fig. 2B). Under normal unstressed conditions (for example, in dense green forests), $r_{\mathrm{a}} \approx 10 \mathrm{~s} \mathrm{~m}^{-1}$ and $r_{\mathrm{c}}$ $\approx 100 \mathrm{~s} \mathrm{~m}^{-1}$, so that evapotranspiration rates calculated by Eq. 6 are almost always much lower than those calculated by Eq. 4 . This effect becomes even more marked when soil moisture is limiting and calculated values of $T_{\mathrm{s}}$ are high.

4) Precipitation interception and interception loss. Vegetation canopies also intercept precipitation, and some can store the equivalent of about a millimeter of water on leaf surfaces. The evaporation of this intercepted water reduces the precipitation input into the soil, reduces the sensible heat flux, and can substantially increase the total evaporation rate. For example, one-third to one-half of the rainfall falling on Amazonia is estimated to be re-evaporated to the atmosphere through interception loss (30).

5) Soil moisture availability. The depth and density of root systems determine the amount of soil moisture available for evapotranspiration. Empirical models were used to relate $f\left(\Psi_{1}\right)$ to soil water content in the root zone, the root density, and the transpiration rate (6).

6) Insulation. The soil surface under a dense vegetation canopy intercepts less radiation and may also be aerodynamically sheltered. For these reasons, the energy available to the covered soil is small, and the component terms of the soil energy budget (evaporation, sensible heat flux, and ground heat flux) are correspondingly reduced.

Global parameter sets for these models were assembled from reports on groundbased ecological surveys (7). Estimates of seasonally varying fields of LAI and greenleaf fraction in these data were used to define global monthly fields of albedo, roughness, and unstressed canopy conductance with the use of a series of simple models. Thus, the important surface parameters were made mutually consistent in these second-generation models; vegetation structure, density, and optical properties were used to determine $\alpha, z_{\mathrm{o}}$, and $r_{\mathrm{c}}(5,6)$. The models were then used to investigate continental hydrometeorology and to conduct some "land cover change" AGCM experiments (16).

The use of second-generation models led to improved simulation of continental hydrometeorology. The results of a run produced by a biophysical model linked to an AGCM were compared with those produced by a conventional bucket hydrology model linked to the same AGCM (31). The continental evaporation rates calculated by the biophysical simulation were consistently lower and in closer agreement with available observations compared with the results from the control run, mainly because of the inclusion of the surface resistance term $\left(r_{c}\right)$ in the biophysical model. These reduced evapotranspiration rates caused reduced and more realistic continental precipitation fields. More recently, a four-layer prognostic soil model coupled to a canopy resistance model (32) and an improved boundary layer model (carefully validated against data from land surface experiments) was introduced into a global forecast model, leading to improvements in the forecast of precipitation over the continents. This improved NWP model realistically simulated the precipitation anomaly that led to the midwestern floods in the United States in the summer of 1993 (33).

A series of "land cover change" simulation experiments directly benefited from the second-generation LSPs. Biophysically based models were used to study the impact of large-scale Amazonian deforestation on the regional and global climate (34). The results from some of these studies show

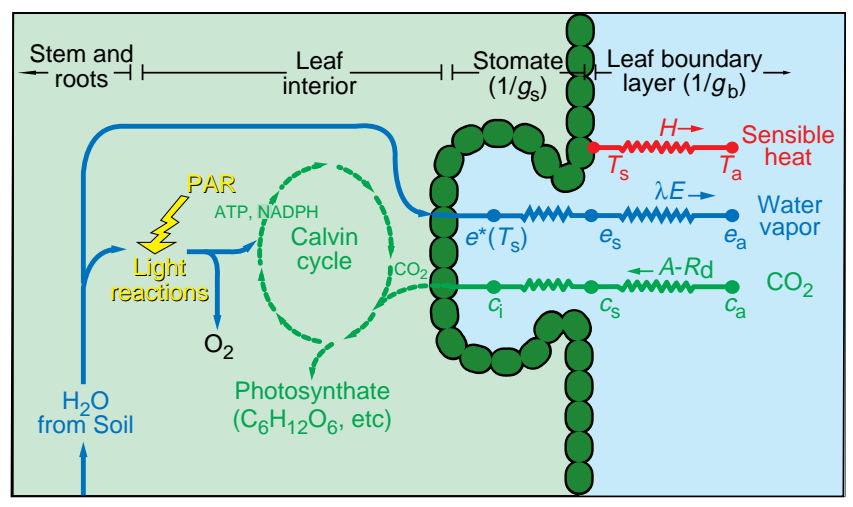

Fig. 3. Schematic of carbon and water exchange in a leaf as conceptualized in a combined photosynthesis-conductance model $(39,40,42$, 43). The stomatal conductance $\left(g_{s}\right)$ is a direct function of photosynthesis, $\mathrm{CO}_{2}$ concentration at the leaf surface $\left(c_{\mathrm{s}}\right)$, and relative humidity at the leaf surface $\left[h_{\mathrm{s}}=e_{\mathrm{s}}\right.$ / $e^{\star}\left(T_{\mathrm{s}}\right) ; e_{\mathrm{s}}=$ vapor pressure at leaf surface] (see Eq. 7). 
decreases in regional evapotranspiration and precipitation linked to increases in surface temperature of around 3 to $5 \mathrm{~K}$ associated with large-scale deforestation. The influence of vegetation on precipitation patterns in the Sahelian region of Africa has also been investigated (35); replacement of seasonal forest and grassland by desert led to a simulated reduction in evapotranspiration and rainfall over the same areas, resulting in a net displacement of the seasonal rainfall patterns to the south.

The effects of spatial or temporal variations in land surface properties have also been studied. The contributions of "mosaics" of different vegetation types within a single AGCM grid square were investigated to explore different averaging schemes; it was found that some straightforward averaging of key parameters could produce results comparable to fully discretized treatments (36). Biophysical LSPs have also been used within mesoscale models to show that sharp variations in land surface properties-for example, forest-agriculture boundaries-may initiate mesoscale circulations under low-wind, high-radiation conditions (37).

The incorporation of biophysics into the second-generation LSPs made them internally consistent, realistic, and capable of calculating surface-atmosphere fluxes more accurately than their first-generation counterparts. However, they were still focused on calculating energy and water budgets because these fluxes have immediate and large effects on the physical climate system as represented in AGCMs. A number of circumstances provided the motivation for the development of more advanced models.

\section{The Carbon Cycle and Third-Generation Models}

By the late 1980s, scientific interest had become focused on global change, particularly on the "greenhouse effect" (global warming) and associated impacts (38). The need for more complete models of the climate system-including biological and chemical processes in the ocean, land, and atmosphere-became apparent.

Plant physiological research made significant advances during the 1980s and early 1990s. A series of biochemical models of leaf photosynthesis were developed that describe $\mathrm{CO}_{2}$ assimilation by chloroplasts or leaves as rate-limited by (i) enzyme kinetics, specifically the amount and cycle time of the carboxylating enzyme Rubisco, (ii) electron transport, which is a function of incident PAR, and (iii) the efficiency of the leaf's light-intercepting apparatus (chlorophyll) (39). These models describe the leaf assimilation (or gross photosynthetic) rate as approaching the minimum of three limiting rates: $w_{\mathrm{c}}, w_{\mathrm{e}}$, and $w_{\mathrm{s}}$, which describe the assimilation rate as limited by the efficiency of the photosynthetic enzyme system (Rubisco-limited), the amount of PAR cap- tured by the leaf chlorophyll, and the capacity of the leaf to export or utilize the products of photosynthesis, respectively.

The physiological limit on assimilation, $w_{c}$, is primarily a function of the leaf's enzyme reserves, which can be thought of as the biochemical processing capacity of the leaf. A model parameter $V_{\text {max }}$ represents the maximum catalytic capacity of the leaf's photosynthetic machinery and determines the upper bound of $w_{c}$; it is directly related to leaf nitrogen content. Significantly, $w_{c}$ is also a direct function of leaf internal $\mathrm{CO}_{2}$ concentration $c_{\mathrm{i}}$, which is itself linked to the $\mathrm{CO}_{2}$ concentration of the external air $c_{\mathrm{a}}$ (Fig. 3). The light-limited rate of assimilation $w_{\mathrm{e}}$ is a linear function of incident PAR and is also dependent on $c_{\mathrm{i}}$; $w_{\mathrm{s}}$ may be defined as a function of the biochemical capacity of the leaf and made proportional to $V_{\max }(40)$.

Field and laboratory studies have documented the tight linkage between leaf photosynthesis and conductance, and theoretical work suggests that stomates function so as to maximize the efficiency of plant water use $(24,41)$. A semi-empirical model of leaf conductance $g_{\mathrm{s}}$ has been proposed (42) (Fig. 2C)

$$
g_{s}=m \frac{A_{\mathrm{n}}}{c_{\mathrm{s}}} h_{\mathrm{s}} p+b
$$

where $m$ is an empirical coefficient from observations $\left(\approx 9\right.$ for most $\mathrm{C}_{3}$ vegetation and $\approx 4$ for $\mathrm{C}_{4}$ vegetation), $\mathrm{A}_{\mathrm{n}}$ is the net
Fig. 4. Global fields used in or generated by a third-generation LSP. (A) Global field of FPAR calculated from AVHRR SVI data (Eq. 9). (B) Canopy transpiration and (C) canopy net photosynthetic productivity (NPP, in grams of carbon per square meter) calculated by a thirdgeneration LSP from within an AGCM, using the FPAR field shown in $(A)(8,48)$. (D) Annual mean $\mathrm{CO}_{2}$ concentration in the planetary boundary layer (55).
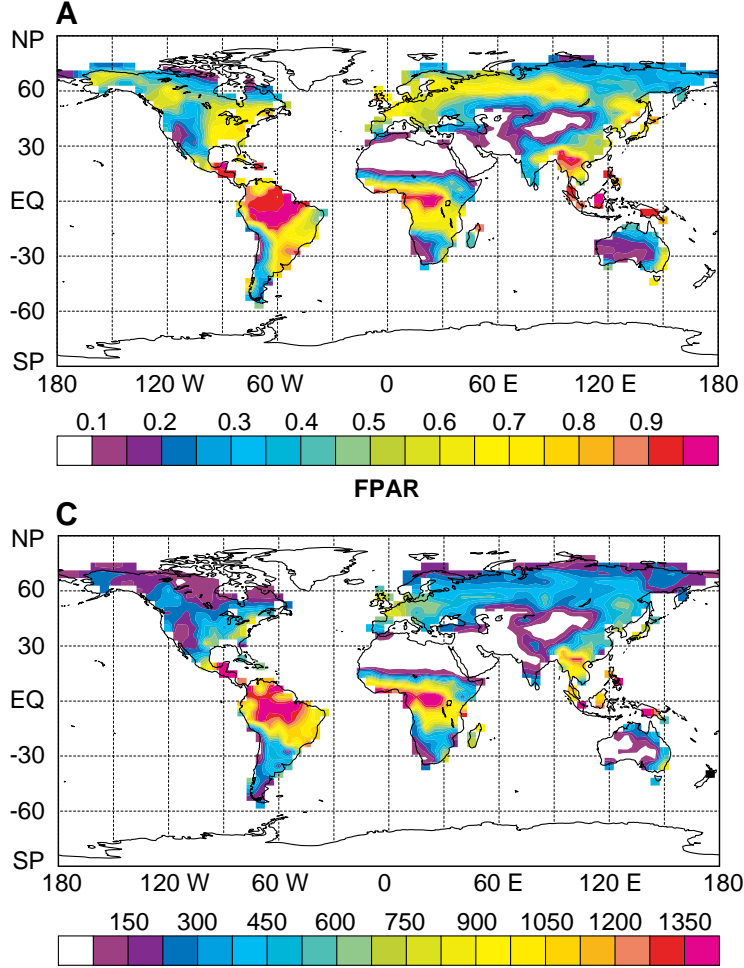

$\operatorname{NPP}\left(\mathrm{g} \mathrm{C} \mathrm{m}^{-2}\right)$
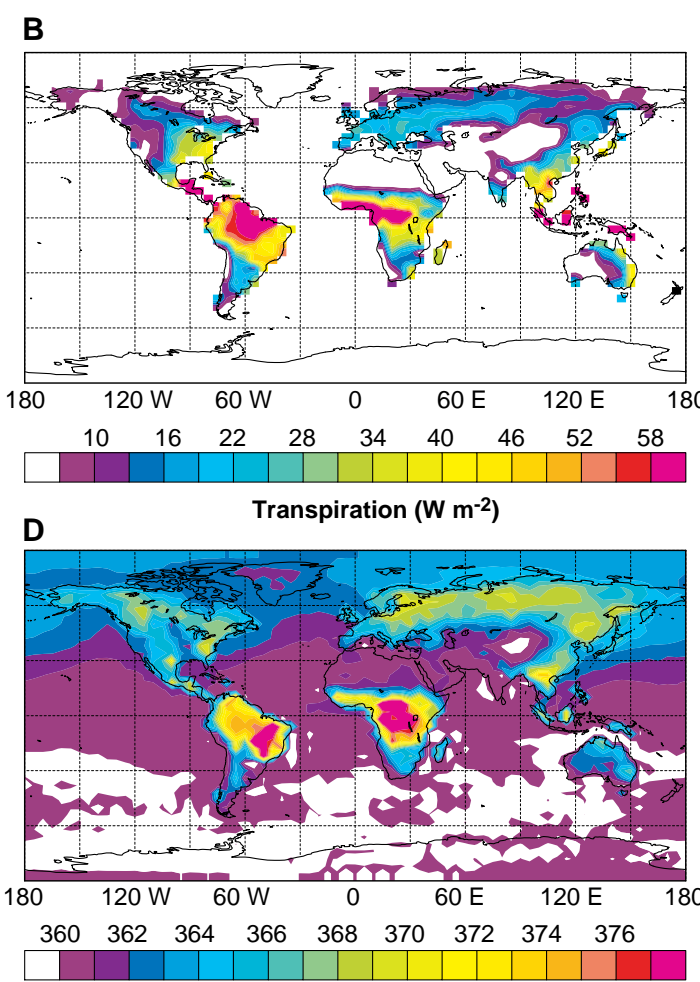

$\mathrm{CO}_{2}$ concentration (ppm) 
$\mathrm{CO}_{2}$ assimilation, $c_{\mathrm{s}}$ is the $\mathrm{CO}_{2}$ concentration at the leaf surface, $h_{\mathrm{s}}$ is the relative humidity at the leaf surface, $p$ is the atmospheric pressure, and $b$ is the minimum value of $g_{\mathrm{s}}\left(\approx 0.01\right.$ for $\mathrm{C}_{3}$ vegetation and $\approx 0.04$ for $\mathrm{C}_{4}$ vegetation). The principal vegetation-dependent parameter defining $A$ is $V_{\text {max }}$, so a total of only three parameters $\left(V_{\max }, m\right.$, and $\left.b\right)$ are used in the calculation of $A$ and $g_{s}$, which is a considerable simplification over the more empirical models of leaf conductance used in the second-generation models. In these new photosynthesis-conductance $\left(A-g_{s}\right)$ models, the partial pressures of $\mathrm{CO}_{2}\left(c_{1}\right.$ and $c_{\mathrm{s}}$ ) and the leaf surface relative humidity $h_{\mathrm{s}}$ are linked to conditions in the canopy air space through $g_{s}$, the leaf boundary-layer conductance $g_{b}$, the net flux of $\mathrm{CO}_{2}\left(\mathrm{~A}-R_{\mathrm{d}}\right.$, where $R_{\mathrm{d}}$ is the leaf respiration rate), and leaf transpiration (Fig. 3). The complete equation set can be solved to yield mutually consistent values of leaf photosynthesis and transpiration.

This leaf-level model can be integrated over the depth of a vegetation canopy and driven by satellite data given a couple of simplifying assumptions (43). The value of $V_{\max }$ has been observed to decrease with canopy depth in parallel with the attenuation of PAR; this arrangement seems to make optimal use of plant nitrogen, which is usually a scarce and valuable resource in nature (41). This relation between the within-canopy profiles of PAR and leaf nitrogen $\left(V_{\text {max }}\right)$ can be exploited to drastically simplify the integration of $A$ and $g_{s}$. The photosynthetic rate and conductance of an entire canopy can be estimated by multiplying a calculation of the performance of the uppermost leaves in the canopy, exposed to the maximum (incident) PAR flux ( $\left.\mathrm{PAR}_{0}\right)$ and hence having the highest photosynthetic capacities $\left(V_{\max }\right)$, by a canopy PAR use parameter, $\Pi=\mathrm{FPAR} / \bar{k}$, where FPAR is the fraction of incident PAR absorbed by the green leaves in the canopy and $\bar{k}$ is the canopy extinction coefficient for PAR. Both FPAR and $\bar{k}$ are time-mean, radiationweighted quantities. The complete set of leaf-scale and canopy-integrated equations governing photosynthesis and conductance can then be summarized as

$$
A_{c}, g_{c}=\left[V_{\max 0}, P R_{0}\right]\left[B_{1} \ldots B_{6}\right][\Pi]
$$

or, reexpressed in words, the canopy scale $A_{c}$ is the leaf physiology or radiation limit times the parameters $B_{1}$ through $B_{6}$. which describe the effects of temperature, humidity, $\mathrm{CO}_{2}$ concentration, soil moisture stress, and so forth on $A_{c}$ and $g_{c}(43)$ ] times $\Pi$ (which varies from zero, for no vegetation cover, to between 1 and 1.5, for dense green vegetation); $g_{c}$ is calculated in a similar manner. The PAR use parameter $\Pi$ is a vegetation property that is amenable to remote sensing $(43,44)$. FPAR and LAI have been related to the so-called spectral vegetation indices (SVI), which are combinations of the radiances (or calculated reflectances) in the visible and near-infrared regions as observed over vegetated land surfaces by satellite sensors (45). Theoretical work $(28,43,46)$ has explored these relations and has demonstrated that the sensor wavebands on the Advanced Very High Resolution Radiometers (AVHRR) mounted on polar-orbiting satellites are well suited for providing SVI values, which should be near linearly related to FPAR over a wide range of conditions. The FPAR term in $\Pi$ should be near linearly related to the simple ratio (SR) SVI when the soil background is dark $(43,46)$

$$
\Pi=\mathrm{FPAR} / \bar{k} \propto \mathrm{SR}=a_{\mathrm{N}} / a_{\mathrm{V}}
$$

where $a_{\mathrm{N}}$ and $a_{\mathrm{V}}$ are the near-infrared and visible reflectances (or instrument counts), respectively (sensor-dependent). The approximate scale-invariance of Eq. 9 is key to its application on large spatial scales, such as in an AGCM. Comparing Eqs. 8 and 9, we see that there is a chain of (near-) linear relations between $A_{c}, g_{c}, \Pi$, FPAR, and SR. Because the area integral of a linear function is proportional to the area of that function over the domain, the mean value of a suitable SVI over a large area (as supplied by a coarse-resolution satellite sensor) should provide good estimates of nonstressed $A_{c}$ and $g_{c}$ over the same area through $\Pi$ in Eq. 8. Global sets of SVI data have been assembled from satellite observations (47) and have been further processed and transformed to provide global $1^{\circ} \times 1^{\circ}$ monthly fields of FPAR (Fig. 4A) and LAI, and hence albedo, roughness length, and $\Pi$, which can be used directly by third-generation LSPs $(8,9$, 48).

The third-generation models $(8,10)$ have some advantages over their predecessors (Fig. 2). First, they are more realistic biologically in that linked $A-g_{s}$ models are used to calculate the coupled fluxes of energy, water, and carbon. These new models also require fewer parameters. Second, an important parameter governing the surface fluxes, $\Pi$, can be obtained continuously, globally, and consistently from satellite data. Third, physiological models can be directly responsive to changes in atmospheric $\mathrm{CO}_{2}$ in a realistic way.

A model that incorporates all of these

\begin{tabular}{|c|c|c|c|c|}
\hline Experiment & $\begin{array}{l}\text { Date of field } \\
\text { phase }\end{array}$ & Location area & $\begin{array}{l}\text { Area of study } \\
(\mathrm{km} \times \mathrm{km})\end{array}$ & Primary foci \\
\hline HAPEX-MOBILHY (51) & 1986 & Southwest France & $100 \times 100$ & Energy-water exchange, mesoscale modeling \\
\hline FIFE (52) & 1987,1989 & $\begin{array}{l}\text { Kansas, } \\
\text { United States }\end{array}$ & $15 \times 15$ & $\begin{array}{l}\text { Energy-water-carbon exchange process studies, } \\
\text { scaling, remote sensing science }\end{array}$ \\
\hline KUREX (57) & 1991 & Kursk, Russia & - & $\begin{array}{l}\text { Energy-water-carbon exchange, remote sensing } \\
\text { science }\end{array}$ \\
\hline EFEDA (58) & 1991 & Central Spain & $100 \times 100$ & $\begin{array}{l}\text { Energy-water-carbon exchange, process studies, } \\
\text { scaling, remote sensing science }\end{array}$ \\
\hline HAPEX-SAHEL (59) & 1992 & Niger, Africa & $100 \times 100$ & $\begin{array}{l}\text { Energy-water-carbon exchange, process studies, } \\
\text { scaling, remote sensing science mescoscale } \\
\text { modeling }\end{array}$ \\
\hline BOREAS (17) & $1993-1996$ & $\begin{array}{l}\text { Saskatchewan and } \\
\quad \text { Manitoba, Canada }\end{array}$ & $1000 \times 1000$ & $\begin{array}{l}\text { Energy-water-carbon exchange, carbon cyle and } \\
\text { biogeochemistry, terrestrial ecology process } \\
\text { studies, scaling, remote sensing science, mesoscale } \\
\text { modeling }\end{array}$ \\
\hline GCIP (60) & $1995-2000$ & $\begin{array}{l}\text { Mississippi basin, } \\
\text { United States }\end{array}$ & $2000 \times 2000$ & $\begin{array}{l}\text { Energy-water exchange, scaling studies, mesoscale } \\
\text { models, application of remote sensing }\end{array}$ \\
\hline LBA (61) & $1998-2000$ & Amazon basin, Brazil & $2000 \times 2000$ & $\begin{array}{l}\text { Energy-water-carbon exchange, carbon cycle and } \\
\text { biogeochemistry, terrestrial-ecology process } \\
\text { studies, scaling, remote sensing science, mesoscale } \\
\text { modeling }\end{array}$ \\
\hline
\end{tabular}

Table 1. Completed and planned large-scale land-atmosphere field experiments. 
features has been used to compare the radiative and physiological effects of doubled $\mathrm{CO}_{2}$ on climate (49). A series of 30-year GCM runs were conducted in which the effects of increased $\mathrm{CO}_{2}$ on stomatal function were simulated in addition to the conventional $\mathrm{CO}_{2}$ "greenhouse effect" (radiative warming of the atmosphere). The impacts were studied separately and in combination. The results indicated that for doubled $\mathrm{CO}_{2}$ conditions, evapotranspiration would drop over the continents and that air temperatures would increase significantly over the tropical land masses, amplifying the changes resulting from atmospheric radiative effects.

\section{Process Studies and the Development of Remote Sensing Techniques}

The process models embedded in LSPs are primarily based on local-scale observations and paradigms. For example, the leaf-scale $A-g_{s}$ models and associated canopy radiative transfer schemes were originally based on studies conducted on spatial scales of a few micrometers (chloroplasts) up to a few meters (a typical soil-vegetation experiment plot). Such submodels were usually applied unchanged and largely untested within AGCMs to describe area-averaged processes over thousands of square kilometers. Some landscape-scale validation of LSPs was seen as being essential (50). It was also recognized that satellite remote sensing offered the most feasible, consistent, and accurate means of providing global fields of land surface parameters, provided that techniques could be developed to rigorously interpret the radiances and convert them into useful biophysical quantities. A series of large-scale field experiments was set up to solve both problems (Table 1). The experiments have been conducted at different times and places and have had differing scientific emphases. However, they all use a nested framework that permits a progressive comparison of measurements made by surface instrumentation (scale: 1 to $10 \mathrm{~m}$ ), surface flux equipment $(10 \mathrm{~m}$ to $1 \mathrm{~km})$, airborne remote sensing equipment (a few hundred meters to several kilometers), airborne eddy correlation (several kilometers), and satellite remote sensing ( $30 \mathrm{~m}$ to global scale). Coverage of a range of biomes (grassland, agriculture, arid zone, boreal forest, and tropical forest) will be achieved over a period of more than a decade (Table 1). The rate of progress has been limited by resource availability and the need for the science community to assimilate the results of these complex experiments as they progress. A number of summary texts have been published for each experiment ( $\mathrm{Ta}$ ble 1 ), so only the salient results are mentioned here.

In general, the local-scale representations of radiative transfer, turbulent exchange, and carbon and water fluxes scaled remarkably well over a wide range of spatial scales. Simple "aggregation" rules can often be used to define effective parameter values over large areas, at least for energy, water, and carbon fluxes over grasslands and temperate and boreal forests $(51,52)$. Satellite remote sensing techniques have been shown to provide useful estimates of surface radiation budget components $\left(S, R_{n}, \varepsilon \sigma T_{s}^{4}\right.$, and sometimes $\left.L_{\mathrm{w}}\right)$, surface reflectances, surface soil moisture, FPAR, and LAI (52). For surface soil moisture, FPAR, and LAI, a series of numerical experiments made use of the fine-resolution data from field observations to compare "aggregate calculations," that is, the sum of many pixel-by-pixel calculations, with "bulk" calculations performed for the same area using average values of the surface and atmospheric forcing parameters. The results agreed to within a few percent and to well within the uncertainties of the estimates provided by averaging surface and airborne eddy correlation measurements ( $\approx 10$ to $20 \%$ ), except for very heterogeneous soil moisture conditions (53). Remote sensing techniques have been improved to the point where global satellite data can be transformed into fields of FPAR, LAI, albedo, roughness length, and other surface parameters and released to the scientific community (54).

\section{Future Directions}

A third-generation LSP-GCM has been used to calculate credible time-series fields of global atmospheric $\mathrm{CO}_{2}$ concentration and realistic surface-atmosphere carbon and water fluxes for a number of instrumented sites around the world $(48,55)$. This kind of simulation, in which physical climate and carbon-cycle processes are directly coupled, will be useful in advancing our understanding of the dynamics of the global carbon cycle.

Diagnostic analyses have shown that the global carbon cycle is intricately linked to the physical climate system. There are indications that the terrestrial biosphere acted as a large sink for atmospheric $\mathrm{CO}_{2}$ during the late 1980s, apparently as a result of anomalies in land surface temperatures, and possibly precipitation anomalies, which led to imbalances in photosynthesis and respiration (56). Large-scale physiological and physical climate system effects will both be important in determining the rate of increase in atmospheric $\mathrm{CO}_{2}$ and the physical and biological responses of the
Earth system to it over the next few decades (49). The need for realistic and accurate models becomes more urgent.

The third-generation LSPs point the way to future land models that can be coupled with comprehensive atmospheric and ocean models to explore different global change scenarios. We expect future models to incorporate better descriptions of hydrology, soil respiration, and ecological responses to climate change than we have today. They will also be required to calculate isotopic fractionation processes as the observed patterns of atmospheric carbon and oxygen isotopes, as well as $\mathrm{CO}_{2}$ and $\mathrm{O}_{2}$ concentrations, can provide insights into carbon cycle dynamics. Running these models over the 1980 to 1995 period, using historical satellite data as boundary conditions, should greatly increase our understanding of the linked energy-water-carbon cycles. In particular, the analysis of model results for anomalous years-for example, years with large air temperature and $\mathrm{CO}_{2}$ concentration excursions-will help us to assess the likely future behavior of the Earth system in response to increasing atmospheric $\mathrm{CO}_{2}$.

\section{REFERENCES AND NOTES}

1. J. T. Houghton et al., Eds., Climate Change 1995, Science of Climate Change, Technical Summary (Cambridge Univ. Press, Cambridge, 1996), pp. 9-97.

2. K. Trenberth, Ed., Climate Systems Modeling (Cambridge Univ. Press, Cambridge, 1992).

3. P. J. Sellers et al., Remote Sensing Environ. 51, 3 (1995).

4. S. Manabe, Mon. Weather Rev. 97, 739 (1969); J. Holloway, J. Leigh Jr., J. Geophys. Res. 80, 1617 (1975); S. Manabe and R. T. Wetherald, J. Atmos. Sci. 44, 1211 (1987); G. A. Meehl and W. M. Washington, ibid. 45, 1476 (1988); J. F. B. Mitchell, in Variations in the Global Water Budget, A. StreetPerrott, M. Beran, R. Ratcliffe, Eds. (Reidel, Hingham, MA, 1983), pp. 429-446; S. H. Schneider and R. E. Dickinson, Rev. Geophys. Space Phys. 12, 447 (1974).

5. R. E. Dickinson, Geophys. Monogr. Am. Geophys. Union 29, 58 (1984).

6. P. J. Sellers, Y. Mintz, Y. C. Sud, A. Dalcher, J. Atmos. Sci. 43, 305 (1986).

7. A. W. Kuchler, Goode's World Atlas (Rand McNally, New York, ed. 16, 1983), pp. 16-17; J. L. Dorman and P. J. Sellers, J. Appl. Meteorol. 28, 833 (1989); E. Matthews, J. Clim. Appl. Meteorol. 22, 474 (1984); J. S. Olson, J. A. Watts, L. J. Allison, Carbon in Live Vegetation of Major World Ecosystems (U.S. Department of Energy, Washington, DC, 1983); C. J. Willmott and K. Klink, in ESA SP-248 (European Space Agency, Paris, 1986), pp. 109-112; M. F. Wilson and A. Henderson-Sellers, J. Clim. 5, 119 (1985).

8. P. J. Sellers et al., J. Clim. 9, 676 (1996).

9. P. J. Sellers et al., ibid., p. 706.

10. G. B. Bonan, J. Geophys. Res. 100, 2817 (1995); R. E. Dickinson, R. Bryant, L. Graumlich, in preparation.

11. W. M. Washington and C. L. Parkinson, An Introduction to Three Dimensional Climate Modeling (University Science Books and Oxford Univ. Press, Oxford, 1986)

12. J. W. Deardorff, J. Geophys. Res. 83, 1889 (1977)

13. R. E. Dickinson, J. Clim. 1, 1086 (1988); D. A. Warrilow, in ESA SP-248 (European Space Agency, Paris, 1986), pp. 143-150.

14. M. I. Budyko, Climate and Life (Academic Press, 
New York, 1974).

15. C. A. Paulson, J. Appl. Meteorol. 9, 857 (1970); M. R Raupach and A. S. Thom, Annu. Rev. Fluid Mech. 13, 97 (1981).

16. J. R. Garratt, J. Clim. 6, 419 (1993).

17. P. J. Sellers et al., Bull. Am. Meteorol. Soc. 76, 1549 (1995).

18. W. J. Shuttleworth et al., Q. J. R. Meteorol. Soc. 110, 1163 (1984); W. J. Shuttleworth et al., ibid., p. 1143

19. J. G. Charney, W. J. Quirk, S. H. Chow, J. Kornfield J. Atmos. Sci. 34, 1366 (1977); Y. C. Sud and M. J. Fennessy, J. Clim. 2, 105 (1982).

20. D. J. Carson and A. B. Sangster, in Numerical Ex perimentation Programme Report (UK Meteorology Office, Bracknell, UK, 1981), no. 2, pp. 5.14-5.21.

21. Y. C. Sud and W. E. Smith, Boundary Layer Meteorol. 33, 15 (1985)

22. Y. Mintz, in The Global Climate, J. Houghton, Ed. (Cambridge Univ. Press, Cambridge, 1984), pp. 79 105; J. Shukla and Y. Mintz, Science 215, 1498 (1982); J. M. Walker and P. R. Rowntree, Q. J. R. Meteorol. Soc. 103, 29 (1977); D. L. Warrilow, A. B. Sangster, A. Slingo, Met 0 20, Tech. Note 38 (UK Meteorology Office, Bracknell, UK, 1986); D. L. Warrilow and E. Buckley, Ann. Geophys. 7, 439 (1989).

23. D. J. Carson, in Proceedings of the JSC Study Conference on Land-Surface Processes in Atmosphere General Circulation Models, P. S. Eagleton, Ed. (Cambridge Univ. Press, Cambridge, 1981), pp. 67108.

24. I. R. Cowan and G. D. Farquhar, Symp. Soc. Exp. Biol. 31, 471 (1977).

25. P. G. Jarvis, Philos. Trans. R. Soc. London Ser. B 273, 593 (1976)

26. P. S. Nobel, Introduction to Biophysical Plant Physiology (Freeman, San Francisco, 1974).

27. R. E. Dickinson, A. Henderson-Sellers, C. Rosenz weig, P. J. Sellers, Agric. For. Meteorol. 54, 373 (1991).

28. P. J. Sellers, Int. J. Remote Sensing 8, 1335 (1985).

29. J. L. Monteith, Principles of Environmental Physics (Arnold, London, 1973).

30. R. E. Dickinson, Rev. Geophys. 33 (suppl.), 217 (1995); K. L. Brubaker, D. Entekhabi, P. S. Eagleson, J. Clim. 6, 1077 (1993).

31. N. Sato et al., J. Atmos. Sci. 46, 2757 (1989).

32. P. Viterbo and A. C. M. Beljaars, J. Clim. 8, 2716 (1995).

33. A. C. M. Beljaars, P. Viterbo, M. J. Miller, A. K. Betts, Mon. Weather Rev. 124, 362 (1996); A. K. Betts, J.
H. Ball, A. C. M. Beliaars, M. J. Miller, P. Viterbo, J. Geophys. Res. 101, 7209 (1996)

34. R. E. Dickinson and A. Henderson-Sellers, Q. J. R. Meteorol. Soc. 114, 439 (1988); A. Henderson-Sellers and V. Gornitz, Clim. Change 6, 231 (1984); C. A Nobre, P. J. Sellers, J. Shukla, J. Clim. 4, 957 (1991) A. Henderson-Sellers et al., J. Geophys. Res. 98 7289 (1993); J. Lean and D. A. Warrilow, Nature 342 411 (1989); J. Lean and P. R. Rowntree, Q. J. R. Meteorol. Soc. 119, 509 (1993).

35. Y. Xue and J. Shukla, J. Clim. 6, 2232 (1991)

36. R. Koster and M. Suarez, J. Geophys. Res. 97, 2697 (1992).

37. J. Noilhan, P. Lacarrere, P. Bougeault, Mon. Weath er Rev. 119, 2393 (1991); R. A. Pielke and R. Avissar, Landscape Ecol. 4, 133 (1990).

38. J. T. Houghton, G. J. Jenkins, J. J. Ephraums, in Climate Change: The IPCC Scientific Assessment, World Meteorological Organization-United Nations Environment Programme, Eds. (Cambridge Univ. Press, Cambridge, 1990).

39. G. D. Farquhar, S von Caemmerer, J. A Berry, Planta 149, 78 (1980); G. J. Collatz, J. T. Ball, C. Grivet, J. A. Berry, Agric. For. Meteorol. 54, 107 (1991); S. von Caemmerer and G. D. Farquhar, in Proceedings of the 1983 Conference at Tallinn, J. Vill, G. Girishina, A. Laisk, Eds. (Estonian Academy of Sciences, Tallinn, 1985), pp. 46-58.

40. For some tropical heat-adapted $\left(C_{4}\right)$ species, the terms $w_{c}$ and $w_{e}$ still refer to Rubisco and light limitations, respectively, but $w_{\mathrm{s}}$ refers to another biochemical (phosphoenolpyruvate carboxylase) limitation [G. J. Collatz, M. Ribas-Carbo, J. A. Berry, Aust. J. Plant Physiol. 19, 519 (1992)]

41. O. Bjorkman, in Plant Physiological Ecology I, vol 12A of Encyclopedia of Plant Physiology, O. L. Lange et al., Ed. (Springer-Verlag, Berlin, 1981), pp. 57-107; T. Hirose and M. J. A. Werger, Oecologia 72, 520 (1987); C. B. Field and H. A. Mooney, in On the Economy of Plant Form and Function, T. J. Givnish, Ed. (Cambridge Univ. Press, Cambridge, 1986), pp. 22-55

42. J. T. Ball, thesis, Stanford University (1988).

43. P. J. Sellers, J. A. Berry, G. J. Collatz, C. B. Field, F. G. Hall, Remote Sensing Environ. 42, 187 (1992).

44. F. G. Hall, K. F. Huemmrich, S. J. Goetz, P. J. Sellers J. E. Nickeson, J. Geophys, Res, 97, 19061 (1992)

45. G. Asrar, M. Fuchs, E. T. Kanemasu, J. L. Hatfield, Agron. J. 76, 300 (1984); C. J. Tucker, B. N. Holben, J. H. Elgin, E. McMurtrey, Remote Sensing Environ.
11, 171 (1981).

46. P. J. Sellers, Remote Sensing Environ. 21, 143 (1987); F. G. Hall, K. F. Huemmrich, S. N. Goward, ibid. 32, 47 (1990); R. B. Myneni, G. Asrar, D. Tanre, B. J. Choudhury, IEEE Trans. Geosci. Remote Sensing 30, 302 (1992)

47. S. O. Los, C. O. Justice, C. J. Tucker, Int. J. Remote Sensing 15, 3493 (1994); C. J. Tucker, I. Fung, C. D. Keeling, R. H. Gammon, Nature 319, 195 (1986).

48. D. A. Randall et al., J. Clim. 9, 738 (1996).

49. P. J. Sellers et al., Science 271, 1402 (1996).

50. S. I. Rasool and H.-J. Bolle, Int. Satell. Land Surf. Climatol. Proj. Rep. 1 (National Center for Atmospheric Research, Boulder, CO, 1983).

51. J.-C. Andre et al., Ann. Geophys. 6, 477 (1988).

52. F. G. Hall and P. J. Sellers, J. Geophys. Res. 100 25383 (1995); P. J. Sellers and F. G. Hall, Eds., ibid. 97 (no. 17) (1992)

53. P. J. Sellers, M. D. Heiser, F. G. Hall, ibid. 97, 19033 (1992); P. J. Sellers et al., ibid. 100, 25607 (1995).

54. P. J. Sellers et al., Bull. Am. Meteorol. Soc. 77, 1987 (1996); B. W. Meeson et al. ISL SCP Initiative I: Global Data Sets for Land-Atmosphere Models, 1987-1988 [CD-ROM] (GSFC-DAAC, NASA Goddard Space Flight Center, Greenbelt, MD, 1995), vols. 1-5 (USA NASA GDAC ISLSCP 001 USA NASA GDAAC ISLSCP_005).

55. A. S. Denning et al., Tellus B 48, 521 (1996); A. S. Denning, D. A. Randall, J. G. Collatz, P. J. Sellers, ibid., p. 543.

56. P. Ciais, P. P. Tans, M. Trolier, J. W. C. White, R. J. Francey, Science 269, 1098 (1995); A. S. Denning, I. Y. Fung, D. A. Randall, Nature 376, 240 (1995); C. D. Keeling, T. P. Whorff, M. Wahlen, J. van der Plicht, ibid. 375, 666 (1995); P. P. Tans, I. Y. Fung, T. Takahashi, Science 247, 1431 (1990).

57. D. Deering and $V$. Kozoderov, in preparation.

58. H.-J. Bolle et al., Ann. Geophys. 11, 173 (1993).

59. J. P. Goutorbe et al., ibid. 12, 53 (1994); S. D. Prince et al., Remote Sensing Environ. 51, 215 (1995).

60. GEWEX Continental-Scale International Project (GCIP) J. Geophys. Res. 101 (no. 3) (1996).

61. J. C. Gash et al., "A Concise Plan for the Large-Scale Biosphere-Atmosphere Experiment in Amazonia," report available from C. A. Nobre.

62. Supported by NASA Earth Observing System funds Sellers-Mooney Interdisciplinary Science Project). We gratefully acknowledge encouragement and support from G. Asrar and D. L. Williams and thank L. East and V. Corey for typing the manuscript.

\section{Make a quantum leap.}

SCIENCE On-line can help you make a quantum leap and allow you to follow the latest discoveries in your field. Just tap into the fully searchable database of SCIENCE research abstracts and news stories for current and past issues. Jump onto the Internet and discover a whole new world of SCIENCE at the new Web address...

\section{http://www.sciencemag.org}

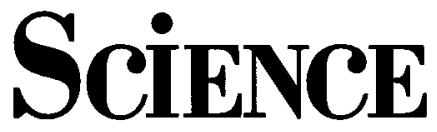

